\title{
The impacts of the global gag rule on global health: a scoping review
}

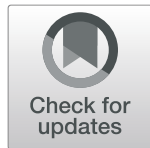

Constancia Mavodza ${ }^{1,2^{*}}$, Rebecca Goldman ${ }^{3}$ and Bergen Cooper ${ }^{4}$

\begin{abstract}
Background: The 1984 Mexico City Policy is a U.S. federal policy that has prohibited foreign nongovernmental organizations that receive U.S. international family planning assistance from using their own, non-U.S. funds to provide, counsel on, or refer for abortion services as a method of family planning, or advocate for the liberalization of abortion laws- except in cases of rape, incest, and life endangerment. The policy became known as the global gag rule (GGR) due to its silencing effect on abortion advocacy. Historically, it has only been attached to family planning funding, until 2017 when a presidential memorandum expanded the policy to nearly all US\$8.8 billion in global health foreign assistance. In light of the aforementioned expansion, this scoping review aimed to describe and map the impacts of the GGR on global health, which in turn would identify research and policy gaps. This is the first time that all of the existing literature on the policy's impact has been synthesized into one article and comprehensively reviewed.

Methods: The review utilized Arksey and Malley's five-stage methodological framework to conduct a scoping review. Fourteen peer-reviewed databases and 25 grey literature sources were searched for publications between January 1984 and October 2017. Organizations and individuals working on GGR research and impact were also contacted to access their works from the same time period. These publications reported on impacts of the global gag rule on 14 domains in global health.

Results: The searches yielded 1355 articles, of which 43 were included. Overall, 80\% of the identified sources were qualitative. The misunderstanding, miscommunication, and chilling effect of the policy underpinned the GGR's impacts. The frequently reported impacts on family planning delivery systems (34 articles) and the loss of U.S. funding (21 articles) were often related. Sources reported on the impact of the GGR on HIV and AIDS programs, advocacy and coalition spaces, and maternal and child health. Only three studies (6.9\%) quantified associations between the GGR and abortion rates, concluding that the policy does not decrease rates of abortion.

Discussion: The GGR's development and implementation was consistently associated with poor impacts on health systems' function and outcomes. More peer-reviewed and quantitative research measuring and monitoring the policy's impact on health outcomes are needed. More research and policy analysis exploring the GGR's development and its implementation on the ground will improve knowledge on GGR consequences, and potentially shape its reform.
\end{abstract}

Keywords: Global gag rule, Mexico City policy, Global Health, Health systems, Abortion

\footnotetext{
* Correspondence: Constancia-Vimbayi.Mavodza@lshtm.ac.uk

${ }^{1}$ Biomedical and Research Training Institute (BRTI), 10 Seagrave Rd, Avondale, Harare, Zimbabwe

${ }^{2}$ London School of Hygiene and Tropical Medicine (LSHTM), London, UK

Full list of author information is available at the end of the article
}

(c) The Author(s). 2019 Open Access This article is distributed under the terms of the Creative Commons Attribution 4.0 International License (http://creativecommons.org/licenses/by/4.0/), which permits unrestricted use, distribution, and reproduction in any medium, provided you give appropriate credit to the original author(s) and the source, provide a link to the Creative Commons license, and indicate if changes were made. The Creative Commons Public Domain Dedication waiver (http://creativecommons.org/publicdomain/zero/1.0/) applies to the data made available in this article, unless otherwise stated. 


\section{Background}

The Mexico City Policy (MCP) has significant impacts on global health and undermines already fragile health systems by disrupting system functions. System disruptions include loss of staff and resources and the reduction of health service provision for populations that need them. The MCP was instated in 1984 by President Ronald Reagan [1]. As a condition of receiving U.S. foreign assistance for family planning, the policy prohibits foreign non-governmental organizations (NGOs) from advocating for the liberalization of abortion laws; or counseling on, referring for, or providing abortion services as a method of family planning [ 1 , 2]. Under the policy, abortion is permissible in the cases of rape, incest, life endangerment of the woman, and as a "passive referral"1 [2]. Since 1984, the policy has been enacted by every Republican president and rescinded by every Democratic president. The policy gags health providers from informing clients of their full range of reproductive options, as well as civil society organizations from advocating for legislative reform. Due to its gagging effect, the policy is often referred to as the Global Gag Rule (GGR), the term used throughout this article.

On January 23, 2017, President Donald Trump reinstated the GGR, renaming it "Protecting Life in Global Health Assistance" (PLGHA), and laying the groundwork for the expansion of the policy to nearly all forms of global health assistance. This includes funding for areas such as HIV and AIDS, maternal and child health $(\mathrm{MCH})$, tuberculosis and malaria, gender-based violence (GBV), health systems strengthening, and water, sanitation and hygiene (WASH) [3].

There is a diverse body of work on past, current, and projected GGR impact, including research articles, projects, reports, and case studies, produced by a wide range of sectors including academic institutions, governments, and health and civil society organizations. A handful of peer-reviewed studies $[4,5]$ and grey literature pieces [6-8] have investigated the impact of previous implementations of the GGR on family planning programs. The expanded GGR has triggered documentation of how this policy has [9, 10] and will affect global health and health systems $[11,12]$.

As part of a larger policy and research report on the GGR, researchers from the Center for Health and

\footnotetext{
${ }^{1}$ The "passive referral" exception permits a health care provider to inform a woman where she can obtain a legal abortion, if all of the following criteria are met: A pregnant woman clearly states that she has already decided to have a legal abortion and asks where one can be obtained, and the provider believes that a response is required based on the ethics of the country's medical profession.
}

Gender Equity (CHANGE) ${ }^{2}$ designed a scoping review that assembles existing evidence on the impact of the GGR on health systems from 1984 to 2017 [13]. This is the first time that all of the existing literature on the policy's impact has been synthesized into one article and comprehensively reviewed. There is sufficient evidence to determine that the GGR is harmful and that there is insufficient existing documentation of all the harms of the policy. Consequently, there is a fragmented understanding of the scope of the GGR's impacts. This constrains knowledge generation for policy development and implementation and underestimates the ripple effect that the policy has had across health system areas.

Facilitating a full mapping and understanding of what is known about the GGR's impacts is critical because it can:

- Identify gaps in evidence generation;

- Reveal how the GGR is conceptualized and understood by the diverse stakeholders interacting with the policy;

- Inform construction of policy for effective health service delivery.

This article outlines the scoping review methodology and the consequent mapping of evidence on the policy's impacts to address the objectives stated above. A discussion on the key findings in relation to evidence generation, existing understanding of the policy, and policymaking is also offered.

\section{Methods}

This review followed Arksey and Malley's five-stage methodological framework: (1) identifying the research question; (2) identifying relevant studies; (3) study selection; (4) charting the data; and (5) collating, summarizing, and reporting the results [14]. A scoping review methodology was adopted as it aims to identify, map, and synthesize key concepts on broad topics, without assessing the quality of the included literature- as would be the case for a systematic review [15]. Currently, there is a dearth of empirical evidence and research on the GGR; and most of the evidence is from non-academic sources as will be seen in the findings of this review. Therefore, the scoping review methodology is most appropriate for mapping the evidence of the GGR's impact. In this research, "impact" is defined as a change or

\footnotetext{
${ }^{2}$ The Center for Health and Gender Equity (CHANGE) is a U.S.-based non-governmental organization whose mission is to promote sexual and reproductive health and rights (SRHR) as a means to achieve gender equality and empowerment of all women and girls by shaping public discourse, elevating women's voices, and influencing the United States Government.
} 
consequence and "health systems" include health care: institutions, resources, services and programs, civil society, advocacy work, providers, health outcomes, and the individuals, and communities served [16].

\section{Identifying the research question}

The preliminary research question for this review was: What is the impact of the Global Gag Rule on health systems? The broad nature of this question was intended to capture the potential breadth of the GGR's impact since its inception, and as well as any impacts recorded since the policy's expansion. CHANGE researchers identified 17 health system focus areas for the review.

\section{Literature search strategy}

A three-step literature search process was performed to exhaustively capture the existing evidence of GGR impact. The established GGR key terms were "Global Gag Rule," "Mexico City Policy," and "Protecting Life in Global Health Assistance." Key and MeSH terms were also established for the selected domains. In the peerreviewed literature search (Table 1), the GGR key terms and the selected domains' (Table 2) key terms were combined using the Boolean term "AND" in all the electronic databases explored (see Table 7 in Appendix).

For the grey literature search, each key term was put into the 25 established websites' publication databases (Table 3) when available, and general search bars when necessary. Different websites required a different number of tab selection, and a unique search strategy was used for one source due to its website format, which required the selection of "Global Gag Rule" from a dropdown menu within its publications tab. In five of the websites, no publications were obtained after using the key terms and search strategy.

Table 1 Peer-Reviewed Literature Electronic Database Sources

- BioMed Central (BMC)
- Google Scholar
- The Lancet
- Population Information Online (POPLINE)
- PsychINFO
- Public Library of Science (PLOS)
- PubMed (ie. MEDLINE)
- ScienceDirect
- Scopus
- Sociological Abstracts (Proquest)
- UNICEF ChildInfo database
- Web of Science
- Wiley Online Library
World Health Organization Institution Repository for Information Sharing
(WHO IRIS)

Table 2: Global Health Domains Searched

1. Abortion
2. Advocacy
3. Commodities (male and female condoms, emergency contraception,
pre- and post-exposure prophylaxis)
4. Family planning
5. Gender-based violence (GBV)
6. Global health assistance
7. HIV and AIDS and STls
8. Human rights
9. Infectious diseases
10. Key populations
11. Maternal morbidity and mortality
12. Maternal and child health (MCH)
13. Non-communicable diseases (NCDs)
14. Orphans and vulnerable children (OVC)
15. Prevention of mother-to-child transmission (PMTCT)
16. Reproductive health
17. Water, sanitation and hygiene (WASH)

Finally, listservs, coalition groups of organizations, and individual researchers known to be doing work on the GGR were contacted to request their work for review inclusion. Additionally, after identifying one institution doing its own scoping review of GGR literature, search results were compared to identify research gaps.

\section{Inclusion and exclusion criteria}

To address time constraints and focus searches, literature was only included if it was available in English and published between 1984 and 2017. Inclusion and exclusion criteria for this review were established and implemented. Inclusion criteria were peer-reviewed journal research articles, organizational reports, working papers, master's theses, and accessible book chapters. Exclusion criteria were fact sheets, policy briefs, blog posts, news articles, press releases, newsletters, opinion pieces, toolkits and advocacy guides, infographics, videos, letters, and transcriptions. Policy briefs were included if they had original findings, such as PAI's case studies of GGR impact within countries, which were internally classified as policy briefs.

\section{Study selection}

The peer-reviewed search strategy identified 1275 articles. Duplicate copies were removed and the remaining articles were screened for relevance by topic area. The established inclusion/exclusion criteria were applied to 297 articles, 148 of which were selected for further screening. Of these articles, the three that did not have full text accessible were removed, leaving 145 articles. 
Table 3 Grey Literature Sources

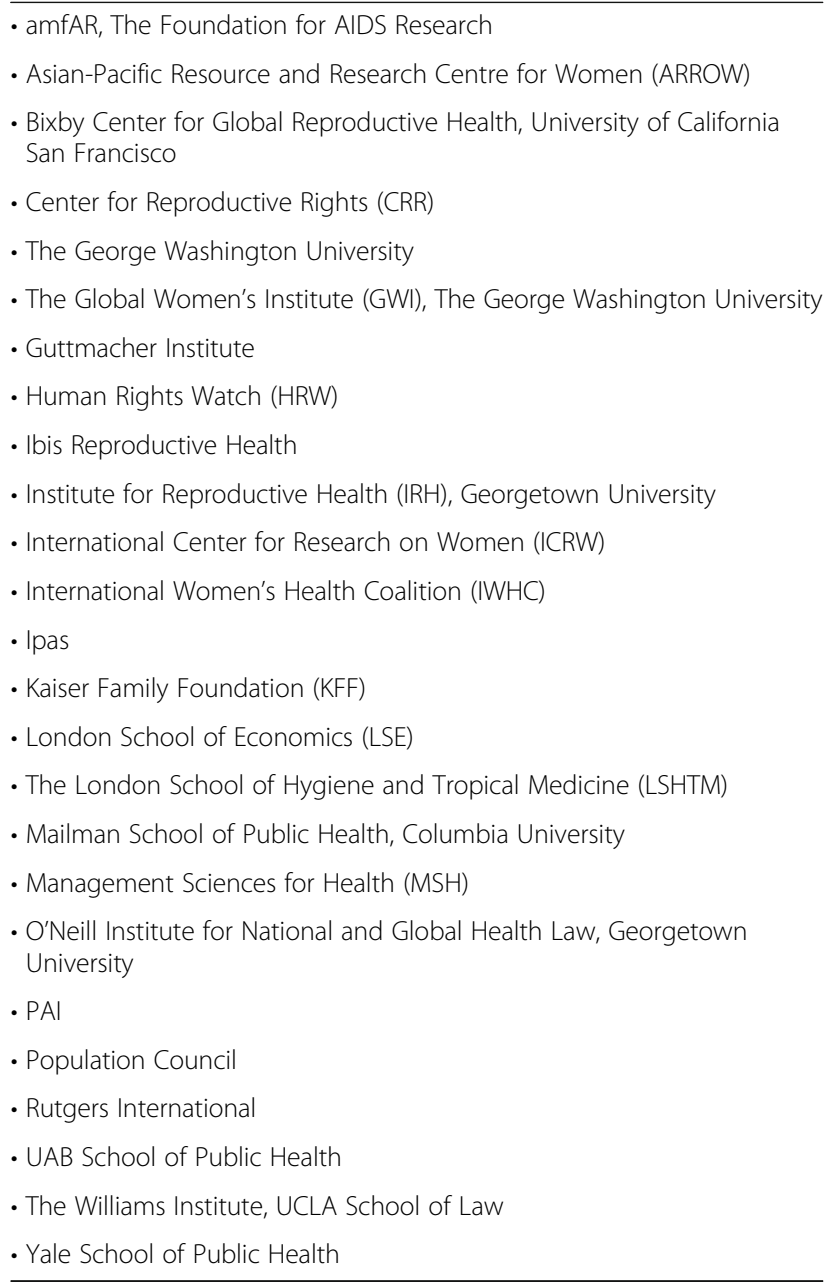

After a full-text reading, an additional 121 articles did not meet the inclusion criteria, and the remaining 24 articles were included in this review. Two additional articles from colleagues were identified and included, resulting in a total of 26 articles for review inclusion (Fig. 1).

The grey literature search strategy identified 75 articles. These were screened using the established inclusion/exclusion criteria and for relevance to yield 17 articles. Four additional eligible articles were identified by colleagues also doing GGR research, and one master's thesis was discovered after the review data collection period, resulting in a total of 22 articles for review inclusion.

All the articles that addressed GGR impact were included, regardless of methodological approach. An article was excluded if it referenced or talked about the GGR without addressing its impact or implications. For example, a Human Rights Watch report on the lack of access to abortion in Peru defined the GGR and recommended that the United States Agency for International
Development (USAID) clarify the policy for the Peruvian government but did not link the GGR to abortion access or other health system indicators, so this article was excluded from the review. The 26 peer-reviewed and 22 grey literature articles were combined, duplicates were removed, and after consultation with an author, one peer-reviewed article was removed due to corrupt data. The peer-reviewed search pulled some pieces that were reports and classified as grey literature. Resultantly, 43 articles addressing the impact of the GGR were included in this scoping review.

\section{Charting the data}

An excel spreadsheet was used as the data extraction summary form to collect general citation information, study type and methodology, country and population of focus, study approach, and key findings on policy impact.

\section{Data collation, analysis, and synthesis}

All 43 articles were read at least twice. CM manually coded and discussed emerging themes with RG and BC. To manage the breadth of the research question and the volume of literature uncovered, narrative descriptive synthesis was used and the findings were classified using the established focus areas (Table 2), allowing for the inductive identification of themes [17]. The focus areas and emerging themes gave structure to the key findings.

\section{Results}

The 43 articles in this review include 16 peer-reviewed publications and 27 grey literature materials (Table 4). Thirty-four pieces are qualitative, and the 9 quantitative include: 3 peer-reviewed publications, one of which looks at the relationship between the GGR and sub-Saharan Africa abortion rates [5], one at donor money allocation, [47] and the third at the relationship between contraceptive supplies and fertility outcomes during GGR years [34]; one working paper on family planning aid in developing countries [18]; a country-specific study on the impact of the GGR on unintended pregnancy, abortion rate, and child health [4]; and a book chapter on the impact of the GGR on abortion rates in four global regions [48]. The remaining 3 quantitative studies are master's theses [24, 30]. Eighteen articles come from just three organizations working in global health. The dominant qualitative approach is a case study, and the quantitative works are largely regression analyses $[4,5]$. Less than half of the literature focuses on specific countries. Most of the literature (86\%) discusses the previous enactments of the GGR and only 7 of the 43 articles are on PLGHA. The reported impacts of the GGR are on: global health assistance, reproductive health services and outcomes, family planning programs, contraceptive supplies and demand, abortion rates, HIV and AIDS 


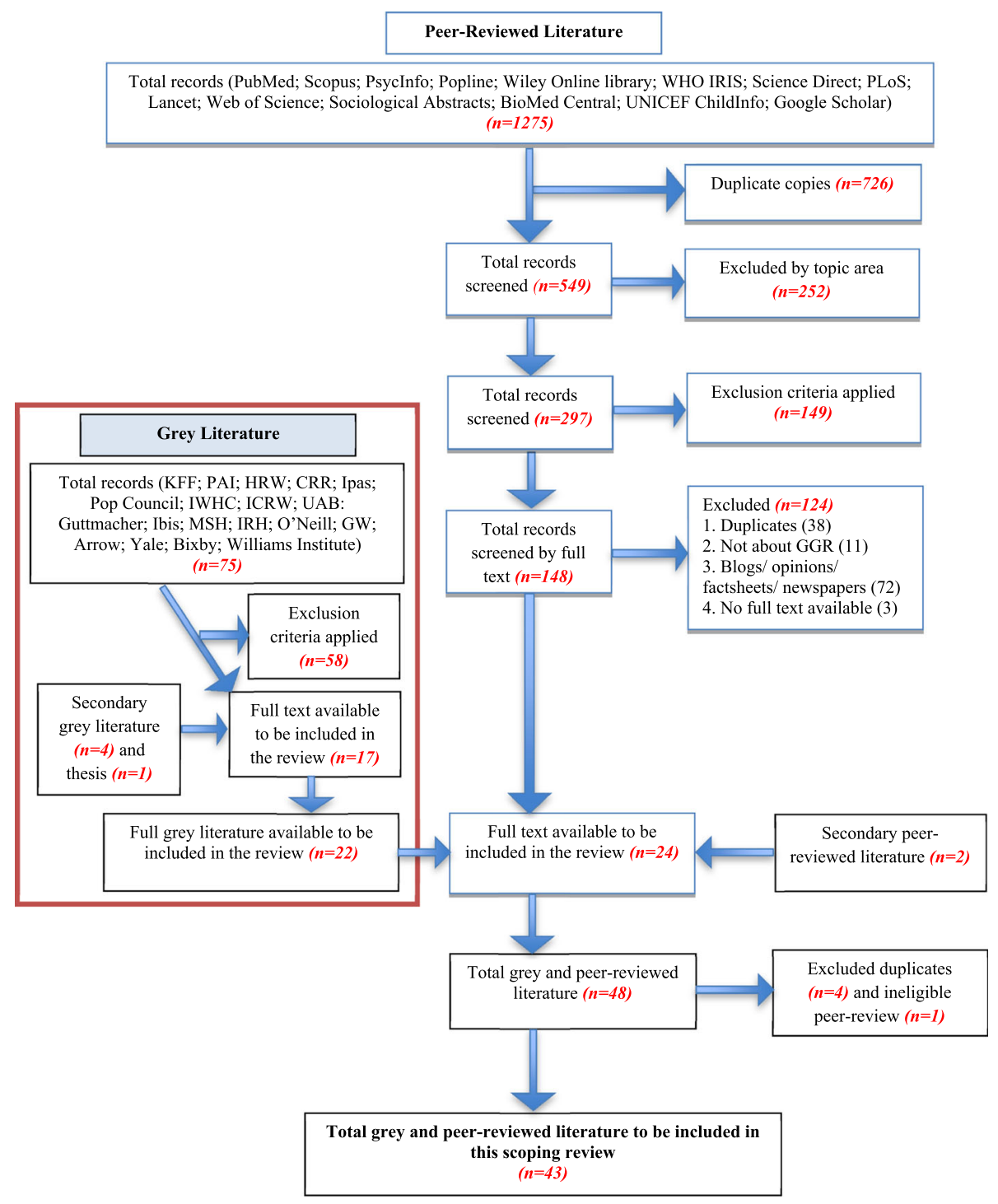

Fig. 1 Search Flow Chart

programs and rates, civil society participation, NGO political advocacy, and human rights.

\section{Misunderstanding the GGR}

Foreign NGOs to whom the GGR applied were confused about the policy $[19,23,49]$. During the Reagan policy years, prime partners in Kenya and Bangladesh were unclear about the practical implementation of the policy, including the permissibility of post-abortion care and the repercussions of non-adherence [19, 38]. During a study visit to Kenya at the time, over $64 \%$ of implementing clinicians interviewed reported that the policy had never been explained to them [19].

Compared to prime non-implementing organizations, sub-prime organizations that interacted with clients tended to be even more confused about the GGR [22,
38]. During the Reagan GGR, an abortion provider in Kenya needed clarity on the permissibility of abortion for a woman living with AIDS, and another questioned if a woman verified by a psychologist to be at risk of committing suicide due to an unwanted pregnancy classified as a case of life endangerment [19]. One organization in Brazil was confused about whether partners advocating for liberal abortion laws could be invited to workshops and receptions, and staff in Bangladesh did not know what abortion research was allowed [19].

\section{Loss of funding}

Twenty-one articles discussed either GGR-associated loss of funding or the outcomes of direct or projected funding loss. International Planned Parenthood Federation (IPPF) [31] and Marie Stopes International (MSI) 


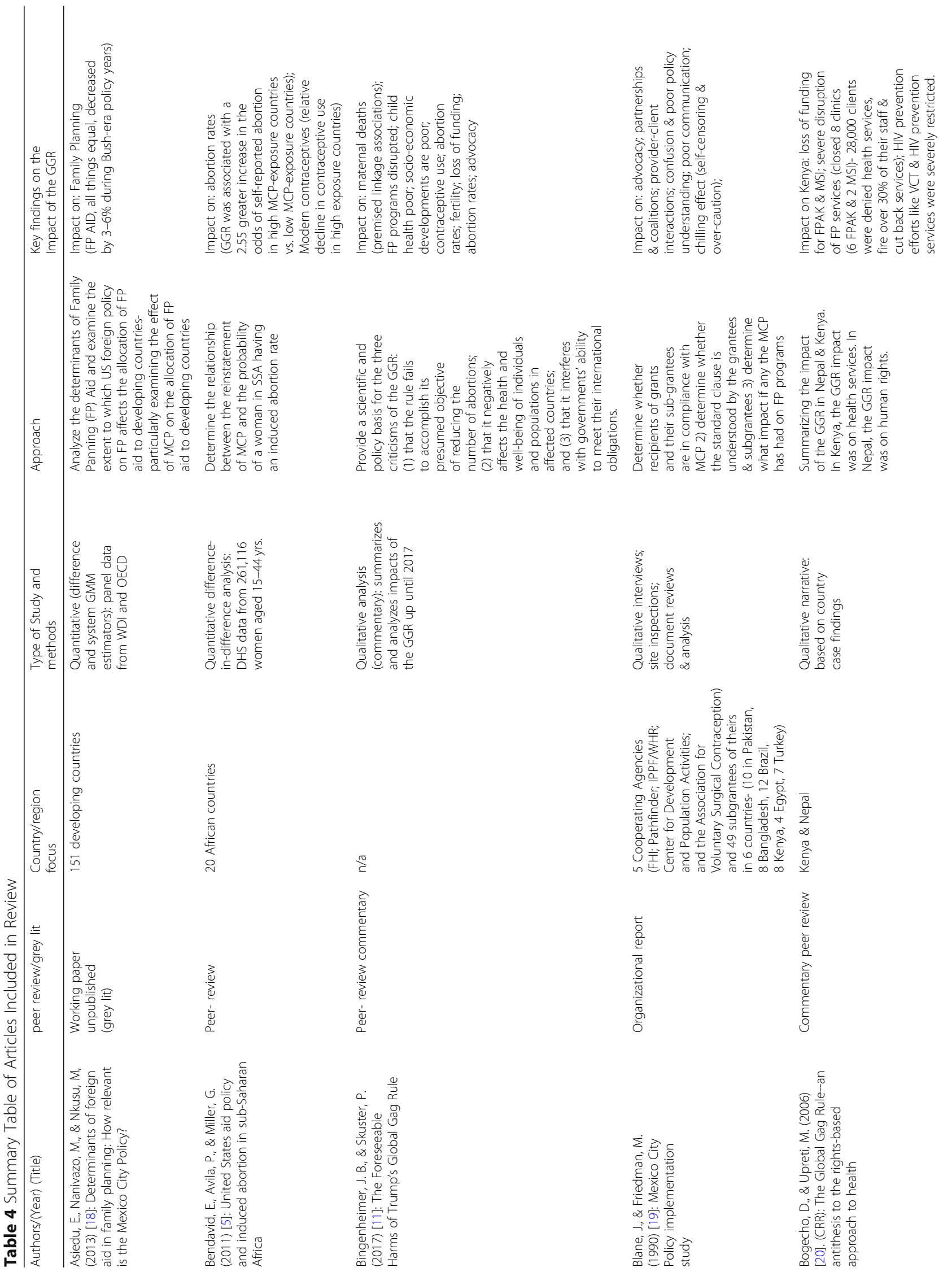




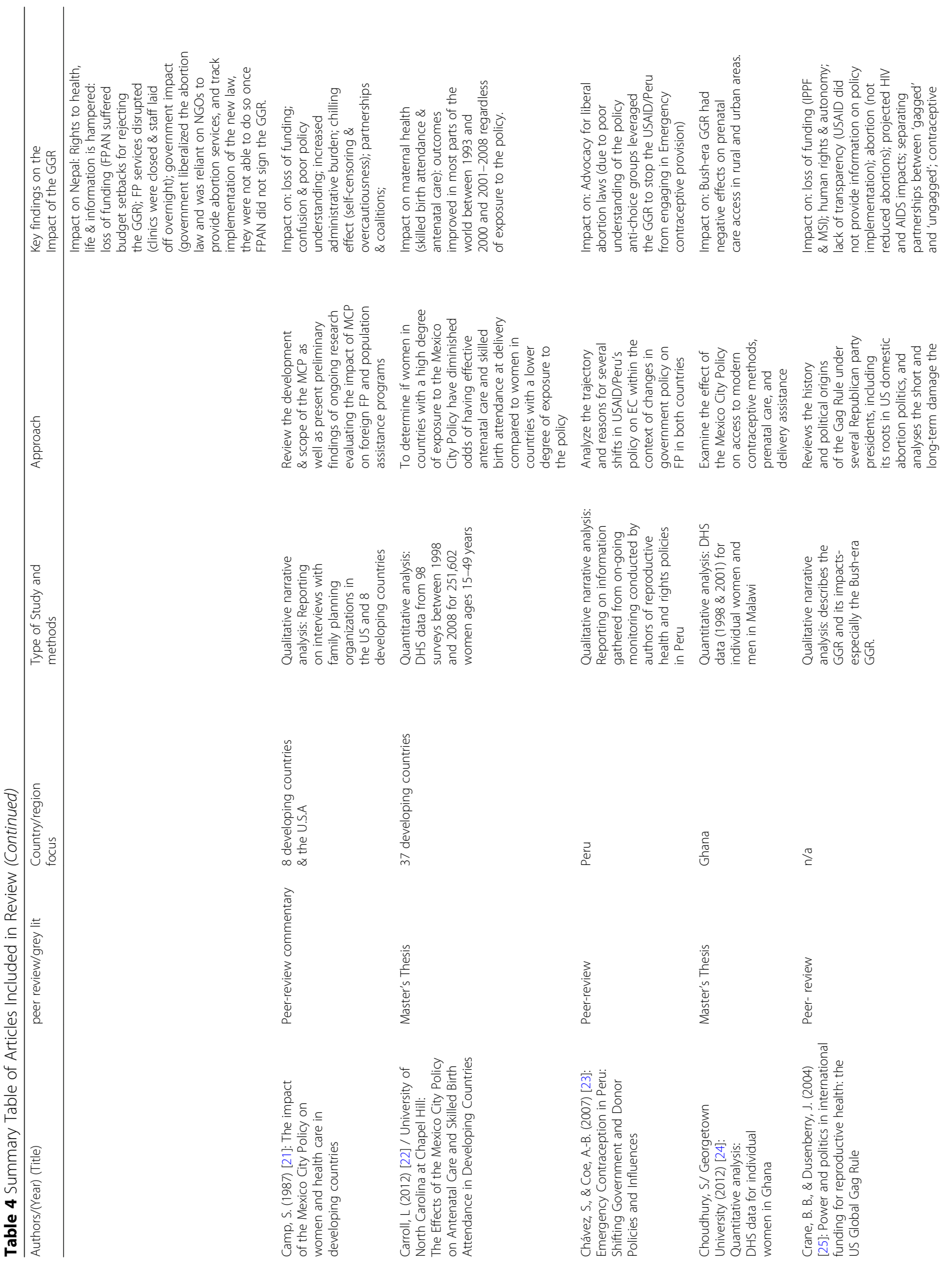




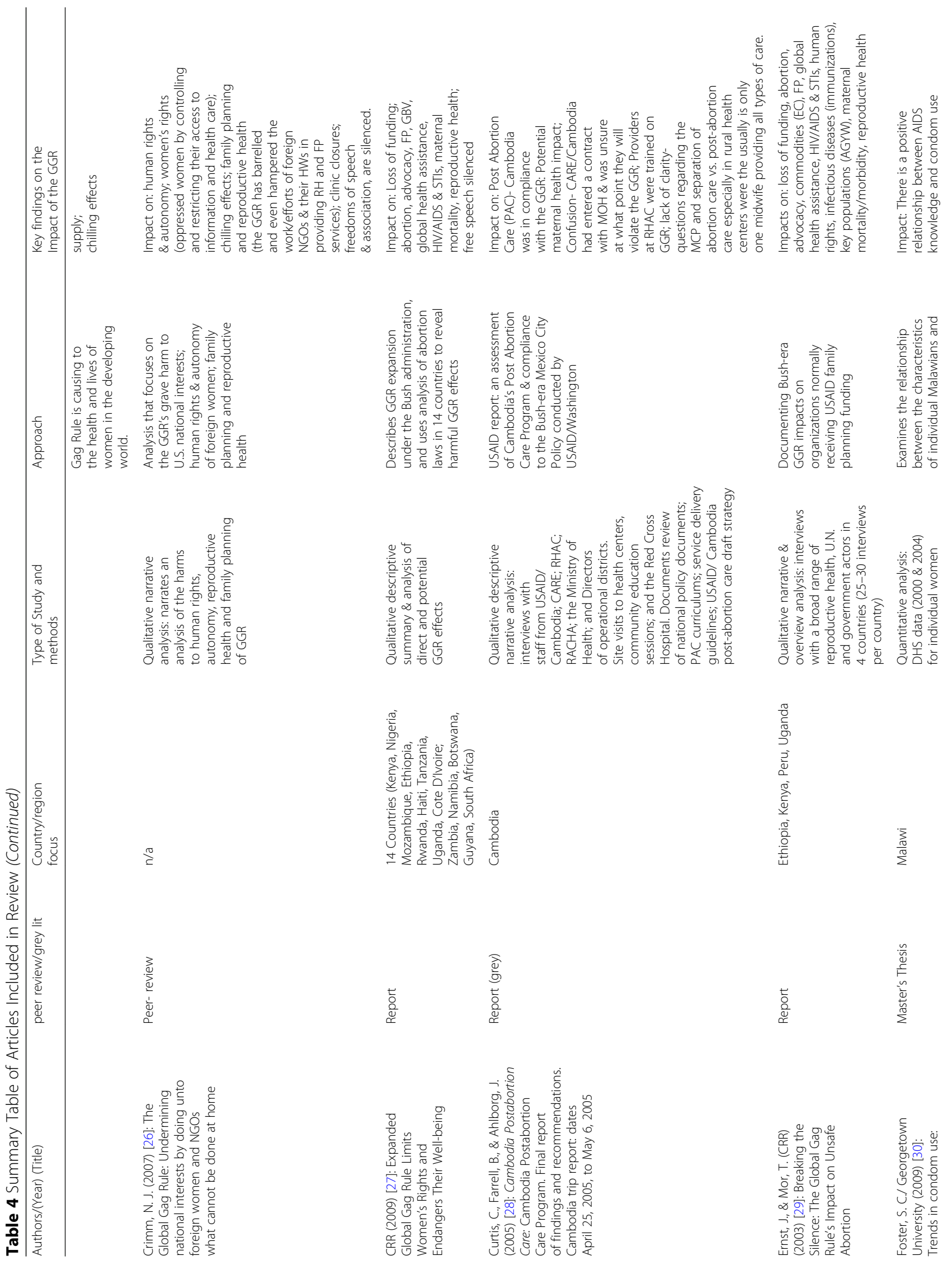




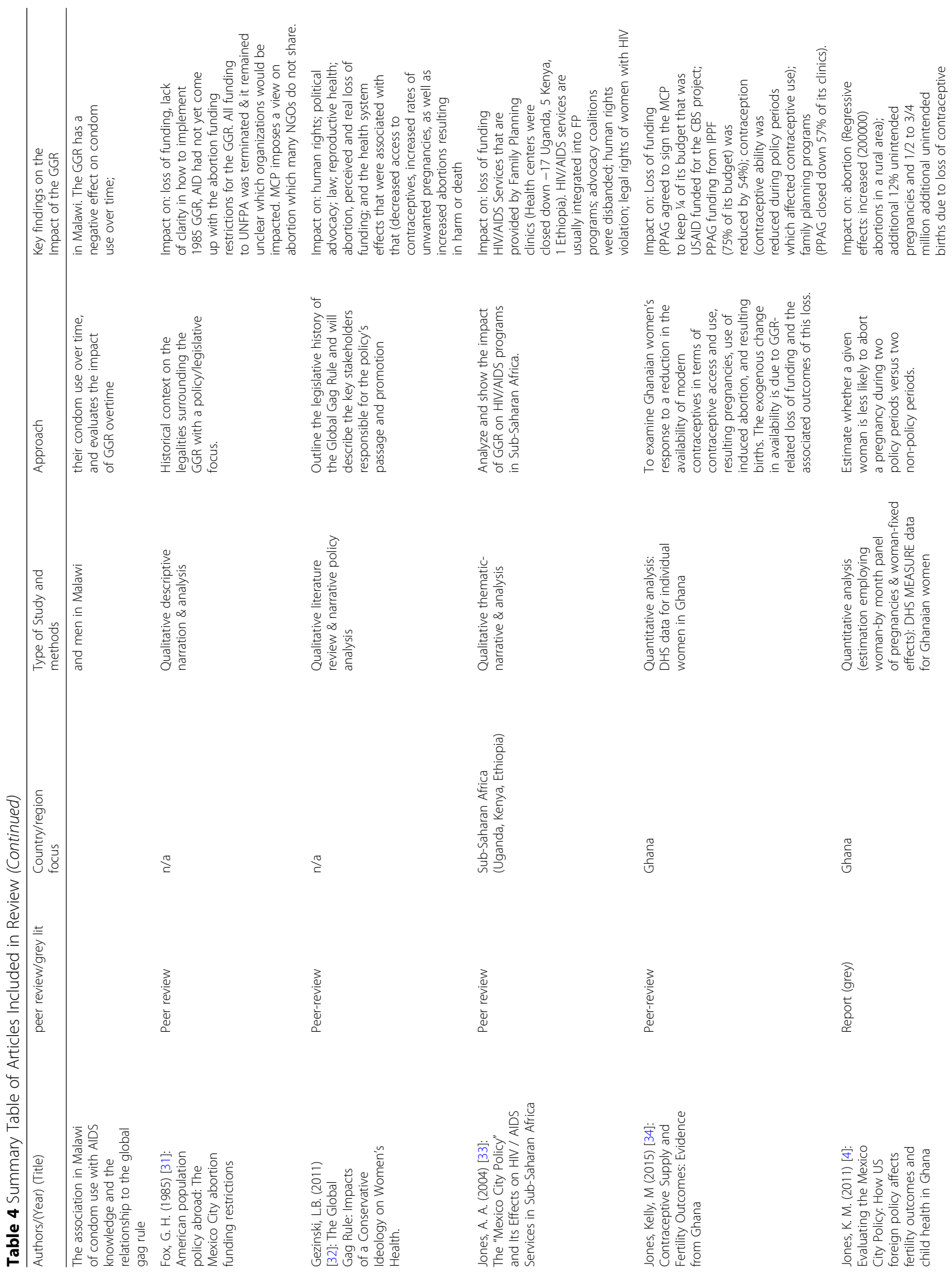




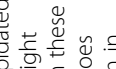

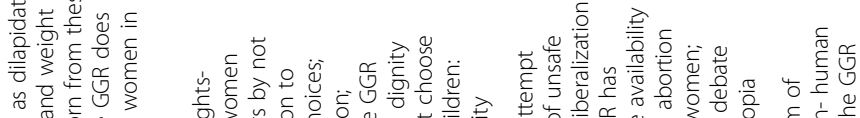

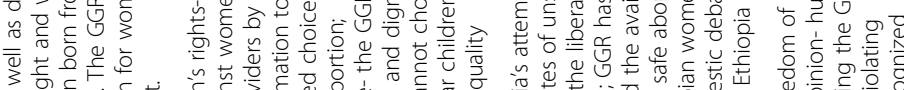

$\begin{array}{llll} & \\ 0 & \end{array}$

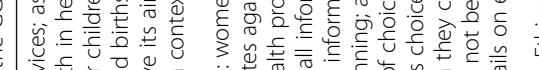

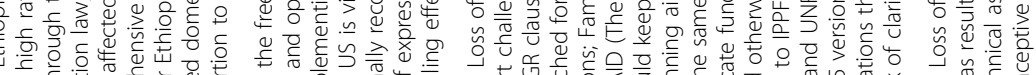

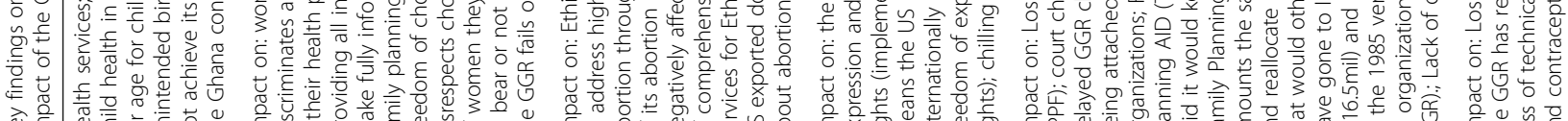
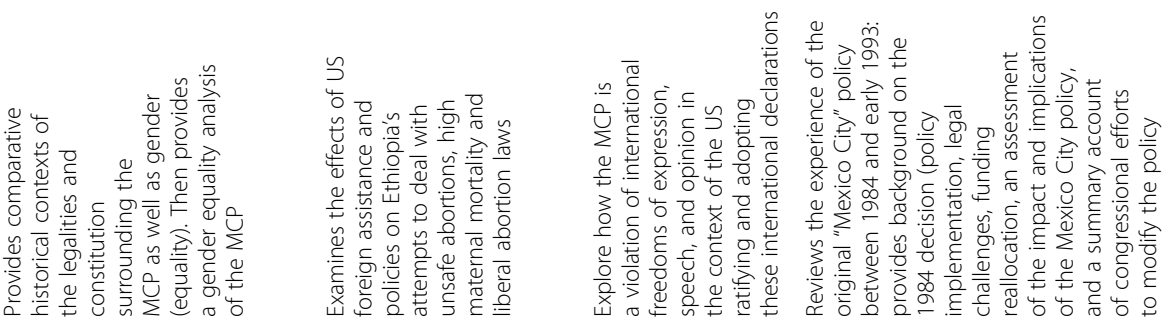

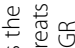

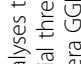

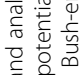

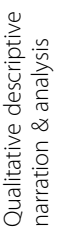
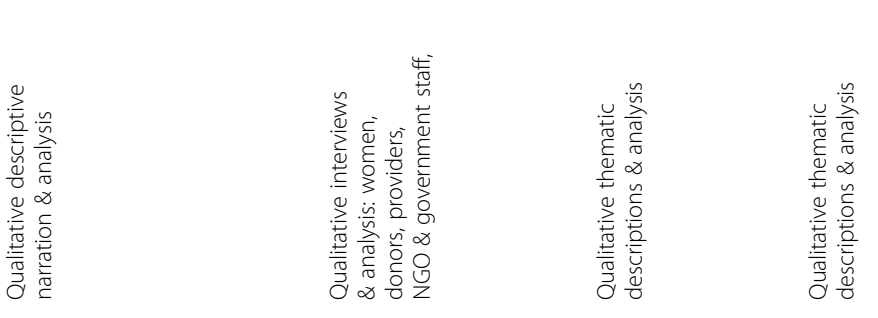

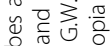

总总䍃

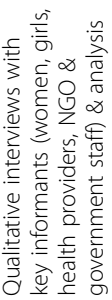

产

$\stackrel{\Xi}{a}$

$\stackrel{0}{\Sigma}$

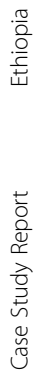

$\stackrel{2}{\check{E}}$

ш

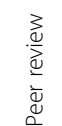

힐

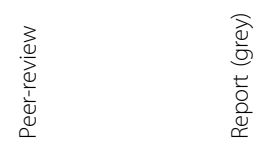

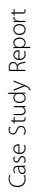
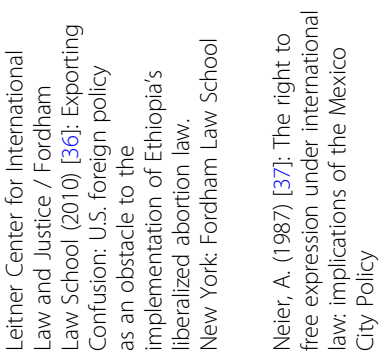

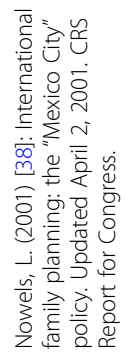

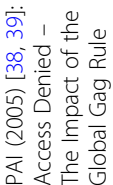




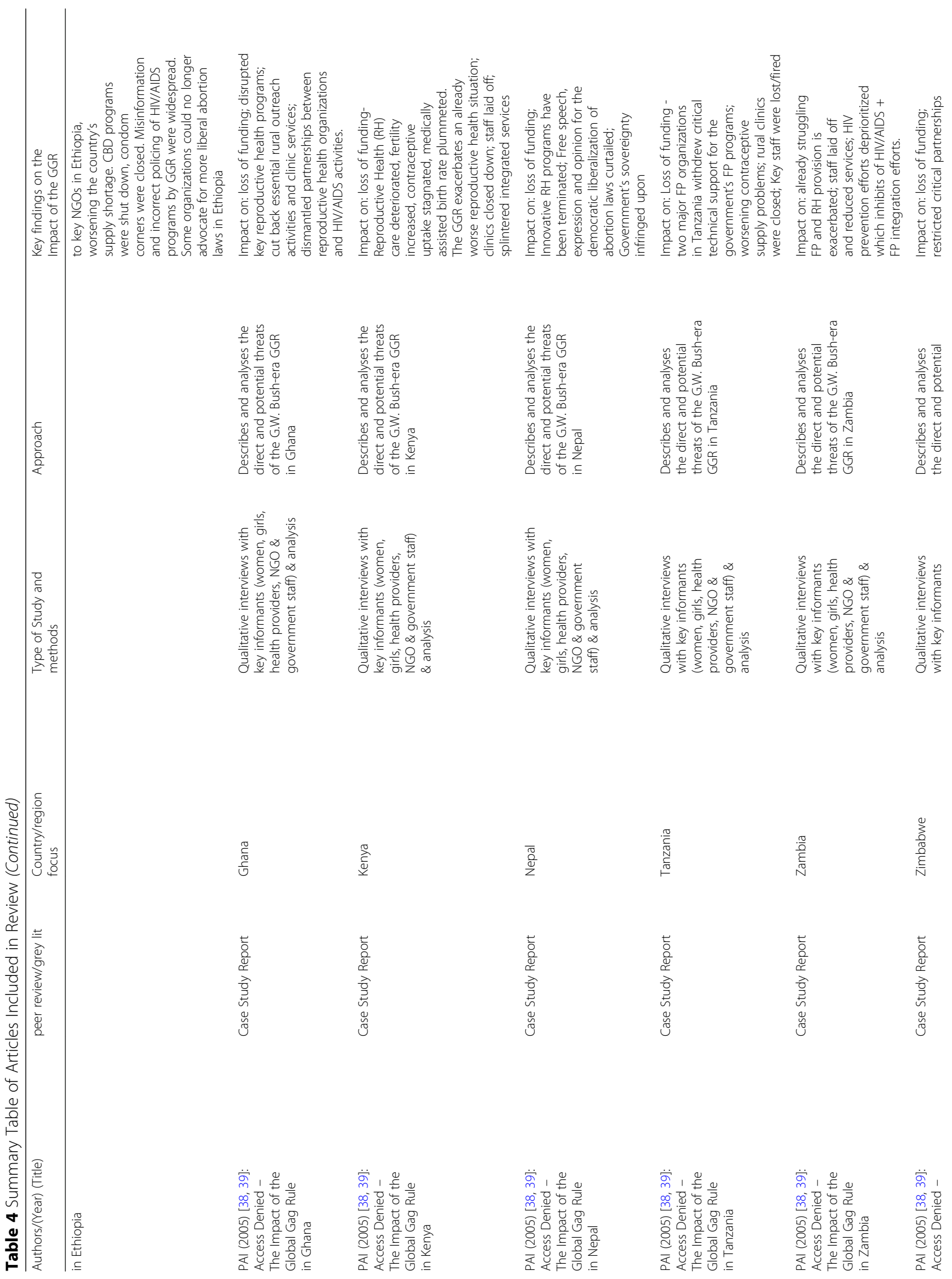




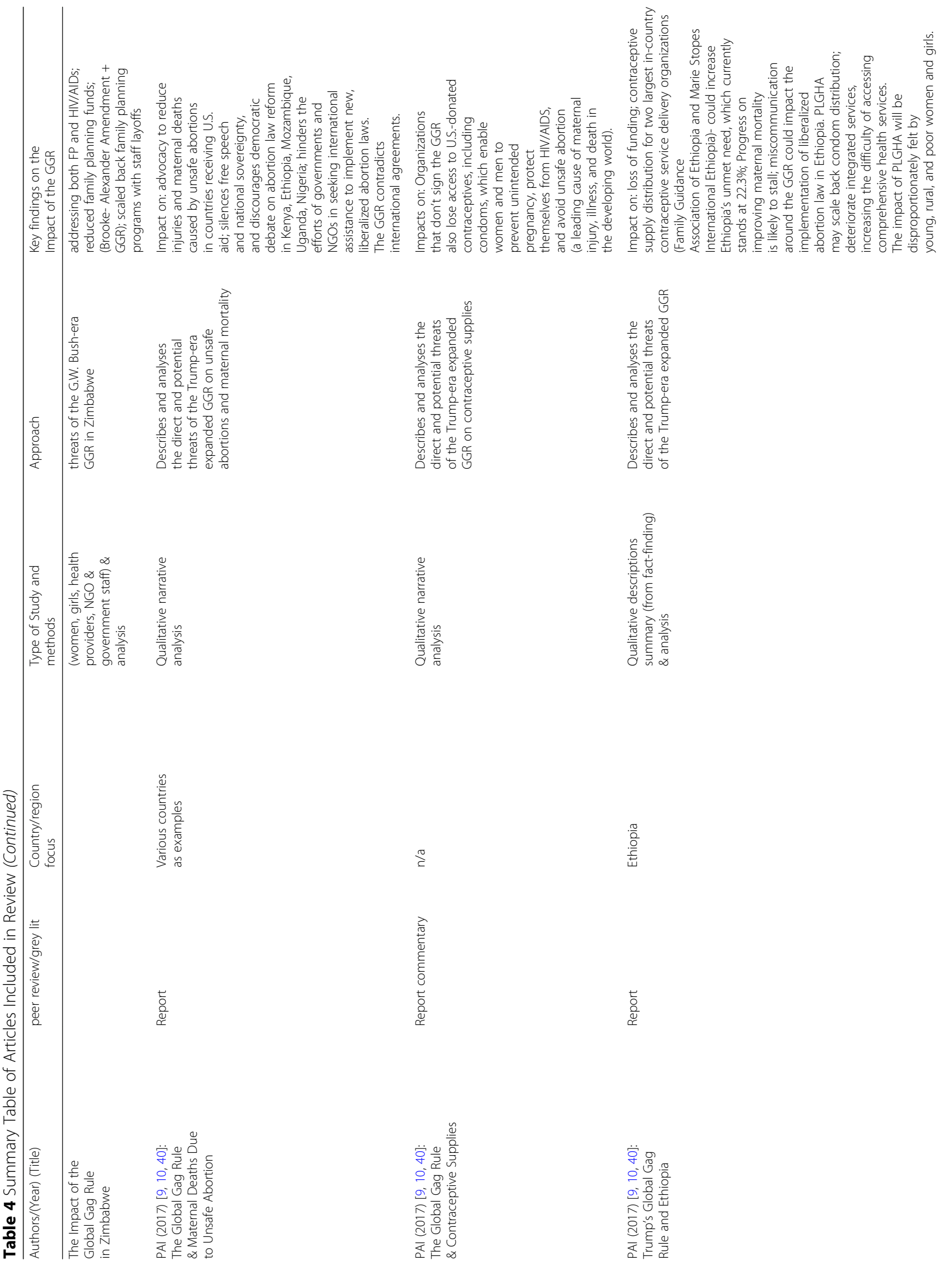




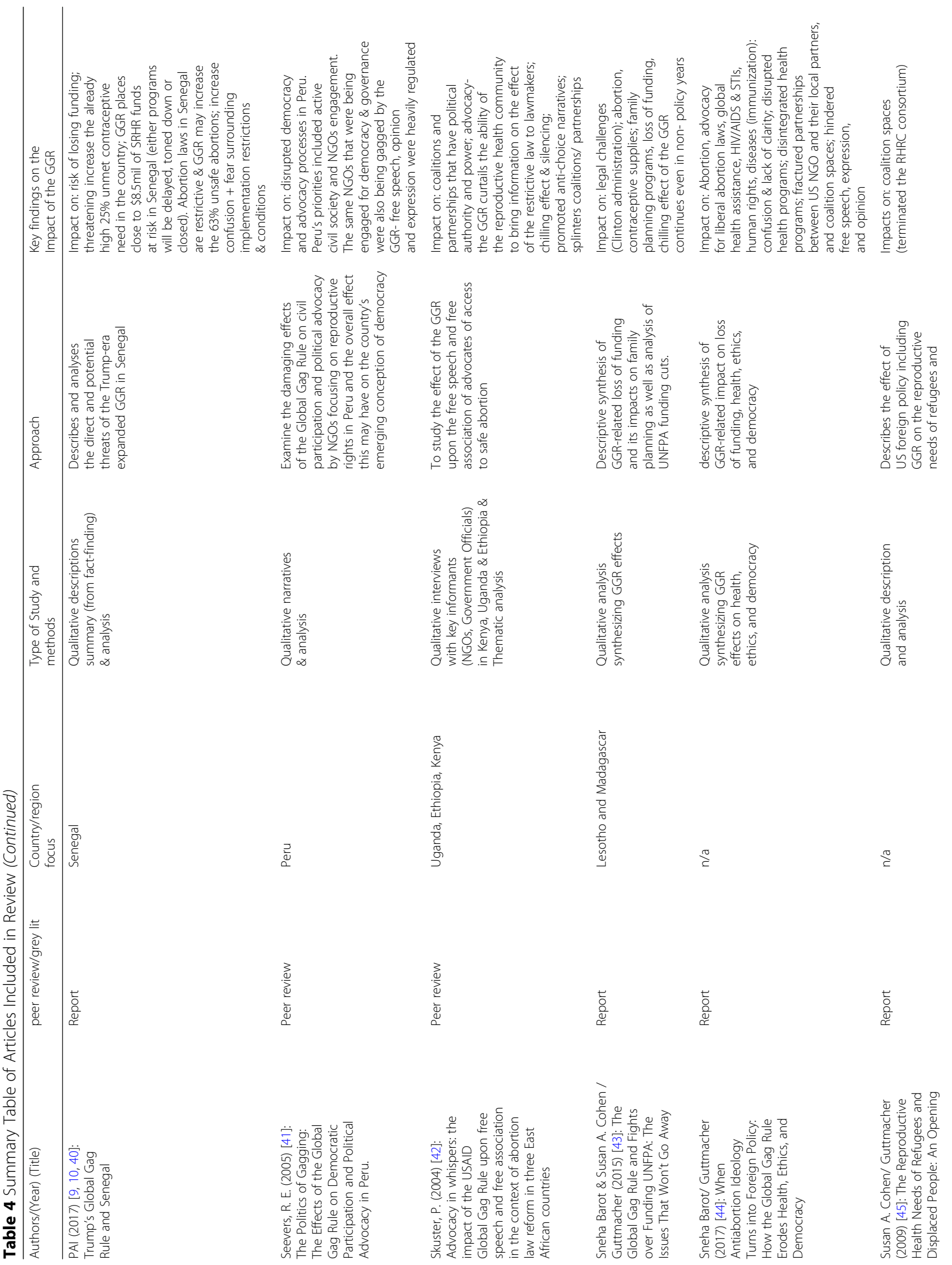




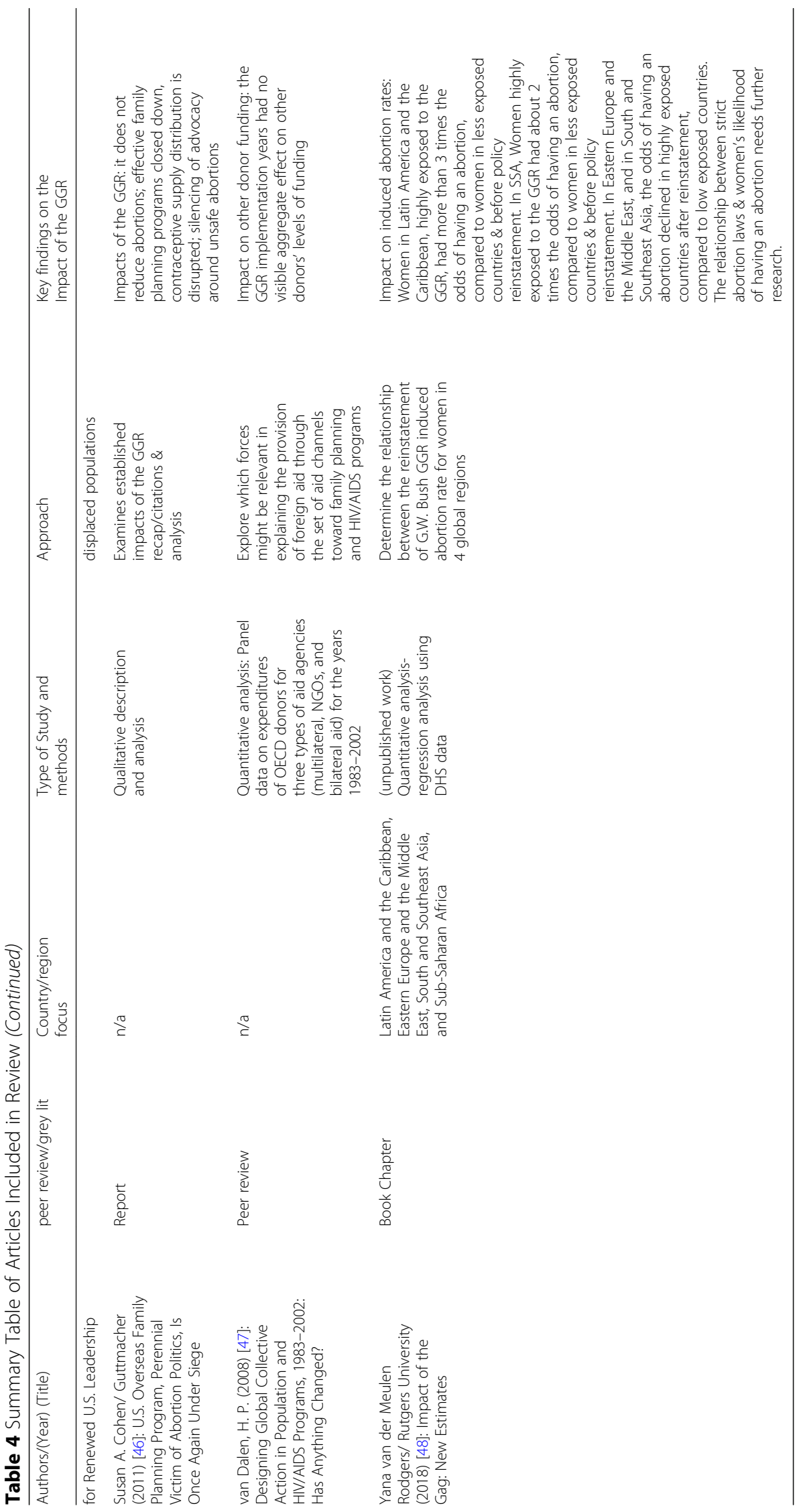


are prime partners who have not complied with any iteration of the GGR, resulting in the recurrent loss of U.S. funding [25]. During the Reagan GGR, IPPF/London's abortion-related work accounted for approximately US\$400,000 annually, though the organization's rejection of the GGR caused them to lose about US\$11 million [26, 38]. During the G.W. Bush GGR, IPPF lost about $\$ 18$ million in U.S. aid annually and consequently had to cut funding to its affiliates, who are sub-grantees. The sub-grantee Family Planning Association of Kenya (FPAK) lost $58 \%$ of its budget, and Planned Parenthood Association of Ghana (PPAG) lost 54\% [34], or US\$200, 000 of funding [39]. Family Planning Association of Nepal (FPAN) lost US\$100,000 in direct funding and US $\$ 400,000$ worth of contraceptive supplies [20], and Family Guidance Association in Ethiopia (FGAE) lost close to half a million U.S. dollars [33, 51]. Organizations that lost funding had to restructure by reducing salaries and laying off staff members [20,43].

Under the Reagan and G.H.W Bush GGR from 1984 to 1993, the U. S government committed to maintaining its level of family planning aid by reallocating the funds denied to non-compliant organizations to those in compliance with the policy [38]. Documentation of this reallocation remains inaccessible despite a 1991 congressional hearing during which USAID reported that reprogramming notifications would be made publicly available $[26,38]$. Under the G.W. Bush GGR, USAID did not provide information on how the policy was implemented [25]. One study reveals that during the G.W. Bush policy years, there was a GGR-associated three to $6 \%$ reduction in U.S. international family planning aid [18]. The most adverse impact on funding was experienced in sub-Saharan African countries [50].

\section{The chilling effect}

The "chilling effect" of the GGR refers to when organizations or health care providers restrict their activities beyond what is required by the policy in order to protect themselves from being accused of non-compliance. In various documented cases, in order to be cautious, providers failed to deliver health services permissible under the policy [23, 41]. In Bangladesh and Turkey, some providers also stopped sharing information on menstrual regulation, and frustrated long-term clients stopped seeking other family planning services that could have benefitted them [19].

Health providers in Egypt ceased all discussions about sepsis after an unsafe abortion, even when this was a major public health concern [19]. An organization in Zambia removed emergency contraception content from its contraception brochure [25]. Some compliant organizations intentionally avoided working with, or requesting proposals from, partners who were not, or likely would reject, complying with the GGR [19, 21]. Others feared even being associated with abortion services, such as a USAID-funded family planning organization in Asia that refused to sell sterilization equipment to a legal abortion clinic, despite the fact that this would not have violated policy requirements [21].

\section{Impact on advocacy and coalition spaces}

In many countries, the GGR hindered efforts to liberalize and implement abortion laws. During the G.W. Bush administration, the same organizations effectively implementing U.S.-funded reproductive health projects in Nepal $[7,43]$ and Peru [41] had been at the forefront of liberalization advocacy. Organizations in Ethiopia, Kenya, Mozambique, Nigeria, and Uganda had initiatives attempting to reform restrictive abortion laws, and received significant U.S. family planning assistance [40]. As a condition of keeping their funding for crucial programs and service provision, the aforementioned organizations were excluded from abortion reform conversations. The GGR also muted the voices of advocates for liberal abortion laws in Kenya and Ethiopia, while anti-choice groups had no such silencing $[29,42]$.

In Peru, the GGR amplified anti-choice groups' narrative against emergency contraception, which resulted in USAID/Peru excusing itself from providing emergency contraception in the country [23]. In Uganda, on the directive of the Catholic cardinal, the government banned emergency contraception across the nation [42].

The GGR also undermined collective advocacy and clinical work during both the Reagan [19] and G.W. Bush $[23,25,42,45]$ policy years as coalitions were often made up of both GGR-compliant and non-compliant organizations. During the Reagan GGR, organizations in Bangladesh that supported menstrual regulation had to fracture their relationships with organizations that did not, which effectively hindered collaborative efforts to promote family planning [19]. Fifteen organizations in Bolivia had banded together to lobby the government on the high national unsafe abortion rate and under G.W. Bush, four of them had to resign due to GGR-related budget threats [33]. The U.S. was the primary donor for the Reproductive Health Response Conflict (RHRC) Consortium, a network of organizations including MSI, which addressed reproductive health for refugees and displaced populations. In 2003, after the GGR was extended to funding from the Department of State, the U.S. ceased RHRC financing [45].

The GGR presented the false choice of continuing to receive funding for programs and services or continuing advocacy work, skewed the debate on abortion and emergency contraception, and fractured partnerships and their collective power to influence change [45]. 


\section{Impact on HIV and AIDS}

The GGR dismantled efforts to provide comprehensive HIV and AIDS prevention, testing, and treatment. In the early years of the G.W. Bush policy era, confusion about policy restrictions led various organizations to cease their HIV and AIDS work in Ethiopia, including the provision of services that were not subject to the GGR [51]. Later during this policy era, the President's Emergency Plan for AIDS Relief (PEPFAR) was conceived and exempt from the GGR. Despite this modification, the current expanded GGR does impact PEPFAR funding.

The GGR undermined HIV service provision by organizations that had integrated family planning and HIV and AIDS efforts [25, 26, 29, 44]. Under G.W. Bush, the GGR affected family planning services like condom education, supply, and distribution, all of which were crucial for HIV prevention [51-53]. After GGR-related funding loss, FPAK and MSI-Kenya curtailed their voluntary counseling and testing (VCT) and HIV prevention services [20].

Due to the GGR, organizations in Uganda were forced to separate abortion from HIV and AIDS services, creating vulnerability for women living with HIV who had unwanted pregnancies [29]. The GGR forced organizations supplying comprehensive, integrated services to choose between silos of either family planning or HIV and AIDS service provision [29].

\section{Impact on abortion}

Three studies have quantified the association between the G.W. Bush-era GGR and induced abortion rates [4, 5, 48]. Bendavid et al. (2011) examined the association between 20 sub-Saharan African countries' exposure to the GGR and induced abortion in women of reproductive age, between 1994 and 2008. Countries that received U.S. financial assistance above a calculated median level were considered to have high GGR exposure. Women in these countries had two and a half times the likelihood of having an induced abortion, compared to women in low-GGR-exposed countries [5].

In a second publication, Jones (2011) evaluated the impact of the policy on induced abortion rates and child health outcomes in Ghana by comparing two periods during which the GGR was in effect (under Reagan and G.W. Bush) to two in which it was not [4]. When the GGR was in effect, abortion rates did not decrease for any demographic, and women living in rural areas had one and a half times the odds of having an induced abortion, compared to women living in urban areas.

A third study implemented the methodology from Bendavid et al. on a global analysis of the association between exposure to the GGR and induced abortion rates [48]. Women in high-exposed Latin American and Caribbean countries had three times the odds of having an induced abortion, compared to women in low-exposed countries. In sub-Saharan Africa, the projections were similar to those found in the Bendavid et al study, with women in high-exposed countries having two times the odds of undergoing an induced abortion, compared to women in low-exposed countries [48]. Together, the available quantitative evidence reveals that GGR implementation was associated with increases in abortion rates, which may be attributable to GGR-based reductions in family planning aid [5] and subsequent reductions in family planning services.

\section{Impact on contraception and family planning}

GGR-related funding losses led to reductions in, or entire shutdowns of, family planning activities and outreach programs. Under the G.W. Bush administration, USAID reduced or stopped contraceptive supplies to 16 countries in sub-Saharan Africa, Asia, and the Middle East [43]. The Lesotho Planned Parenthood Association (LPPA), the only distributor of condoms in the country, did not receive U.S. condom supplies for almost eight years [43]. "Condom corners" that supplied free condoms to rural communities in Ethiopia, Ghana, and Kenya closed down, resulting in contraceptive supply shortages $[6,39,40]$. MSI decreased services and closed clinics in Kenya [6, 20, 33], Tanzania [52], Uganda [33], and Zimbabwe [53]. IPPF closed down clinics in the Democratic Republic of the Congo, Ethiopia, Ghana, Kenya, Zambia, and Zimbabwe [6, 8, 20, 39, 51, 53]. Planned Parenthood Association of Ghana closed 57\% of their clinics, and rural areas in Ghana experienced a $45 \%$ drop in community-based distribution of contraceptive supplies [34]. Some health facilities offering a range of integrated services, including family planning, were the only providers of primary health care, so their closure dissolved communities' only contact with the health system [50].

From 2001 through 2008, the family planning funding that IPPF lost could have prevented 36 million unintended pregnancies and 15 million induced abortions [43]. Dismantling family planning programs triggers the decrease in contraceptive supplies [34] and modern contraceptive use [5], and an associated increase in unintended pregnancies [4]. Jones' study revealed an association between GGR-related funding loss and an estimated $12 \%$ increase in rural pregnancies and 500, 000 to 750,000 additional unintended births, which may be attributable to the reduction of the community-based distribution of contraceptive supplies [4].

\section{Impact on maternal and child health}

Jones' estimations reveal that children born from unintended pregnancies related to GGR exposure had poorer health status on height- and weight-for-age indicators 
when compared to their siblings [4]. Additionally, a master's thesis found that under G.W. Bush, GGR exposure in Ghana had negative effects on prenatal care access for both rural and urban populations [24], which could have been linked to the shutdown of facilities run by organizations like MSI [39]. Bingenheimer \& Skuster (2017) hypothesize that the negative outcomes of the GGR implementation, including an increase in unsafe abortions and decrease in health system access, could likewise have negative repercussions on maternal morbidity and mortality [11].

\section{Discussion}

To our knowledge, this is the first comprehensive scoping review to track and coalesce the impacts of the GGR from its inception to 2017. This review provides a preliminary mapping of the vast impacts of the policy across health systems, which researchers and policymakers can use as the first step in their GGR work. This review also reveals that the GGR is a poorly constructed and implemented policy (Table 5).

Public policy literature demonstrates the crucial importance of preparation and planning when creating [54] and implementing policies [55, 56]. Decisionmaking on the content of the GGR neglected to consider all the actors who would be involved with the policy's implementation, as evidenced by the resulting miscommunication and misunderstanding on compliance requirements. Studies have shown that when critical stakeholders are excluded from agenda-setting and/or the policy formulation process [57], desired policy outcomes may fail to emerge $[58,59]$. In the scoped literature, there is no evidence to suggest that organizations to whom the policy applies were present when crafting the Standard Provisions, and a plethora of evidence reveals that the policy does not have its stated intended outcome of reducing rates of abortion and saving lives.

GGR decision-makers have not given adequate attention to the contextual understanding necessary for implementing the health system changes mandated by the policy [60], which may partially explain the miscommunication between U.S. prime partners and their sub-grantees (Table 6). Prime partners operating at

Table 5 Prime Partners and Sub-grantees

A "prime partner" is an organization that receives U.S. funding directly from the U.S. government. Both U.S.-based NGOs and foreign NGOs can be prime partners. All U.S. funding and policy requirements are passed down from prime partners to their sub-grantees.

A "sub-grantee," "sub-recipient," or "sub-prime" is an organization that receives U.S. funding from a prime partner, rather than directly from the U.S. government. Sub-grantees are one step removed from a direct relationship with the U.S. government, and communications about their funding are filtered through the prime partner.
Table 6 The GGR- a poorly constructed and implemented policy

- There is no available documentation of all the actors involved in crafting the GGR.

- Preparation and planning for the implementation of the GGR are generally poor.

- Confusion about the GGR presents differently for stakeholders at the micro, meso, and macro levels of the health system.

- Implementation of the GGR takes a top-down approach with no bottom-up input.

- Since its inception, the GGR has had harmful impacts on more than just family planning, including miscommunication and misunderstanding of policy mandates; segregation of integrated systems; loss of funding and staff; gaged advocacy; disrupted health delivery systems; and reduced health service provision.

the macro-level of the health system may understand what policy compliance entails because they have direct communication with the U.S. government. Subgrantees at the meso level of the health system are implementing GGR-constrained services without having direct contact with the U.S. government and may be less informed about the GGR. The health care providers operating at the micro-level of the health system have to make decisions informed by the GGR, and yet they are so far removed from policy compliance standards. When the multiple and interacting levels of the health system must confront the GGR, there is ample opportunity for miscommunication, confusion, and chilling effects. For example, in a country like South Africa, in which abortion is permitted upon request [61], imposing the GGR generates confusion and fear as providers negotiate between local law and GGR compliance.

The recent expanded GGR worsens the confusion surrounding this policy as it also applies to non-family planning global health stakeholders. In 2003, President G.W. Bush authorized PEPFAR to spend up to US $\$ 15$ billion over five years to address HIV and AIDS, tuberculosis (TB), and malaria [62]. In its first four years, PEPFAR reduced AIDS-related deaths by about 10.5\% [63] and has supported the provision of antiretroviral therapy (ART) for about 14.6 million people since its inception [64, 65]. When G.W. Bush issued a presidential memorandum to reinstate the GGR, it specified that the policy would not apply to PEPFAR funding. In 2017, President Trump issued a presidential memorandum to reinstate and expand the GGR, which no longer excludes funding through PEPFAR, threatening almost one and a half decades of progress combating HIV and AIDS. Newly published research indicates that the GGR is already harming PEPFAR efforts $[16,66]$. Potential financial impacts of the GGR on programs like PEPFAR that include education and prevention of HIV and AIDS may mean that more resources will be needed for treatment. 


\section{Appendix}

Table 7 Search Terms \& Key Words per Focus Area

\begin{tabular}{|c|c|c|}
\hline Key Topics & $\mathrm{MeSH}$ & $\begin{array}{l}\text { key search words (keywords will be } \\
\text { searched TIAB search filter) }\end{array}$ \\
\hline Global Gag Rule & none & $\begin{array}{l}\text { "Global Gag Rule" OR "GGR" OR "Mexico } \\
\text { City Policy" OR "Protecting Life in Global } \\
\text { Health Assistance" }\end{array}$ \\
\hline Abortion & $\begin{array}{l}\text { "Abortion, Induced" OR "Abortion, } \\
\text { Septic" OR "Abortion, Criminal" }\end{array}$ & abortion \\
\hline Advocacy & "consumer advocacy" & Advocacy \\
\hline $\begin{array}{l}\text { Commodities (male } \\
\text { \& female condoms; } \\
\text { PrEP; Emergency } \\
\text { Contraception: PEP) }\end{array}$ & $\begin{array}{l}\text { "Condoms" OR "Condoms, Female" OR } \\
\text { "Pre-Exposure Prophylaxis" OR } \\
\text { "Contraceptives, Postcoital" OR "Post- } \\
\text { Exposure Prophylaxis" }\end{array}$ & $\begin{array}{l}\text { condoms OR female condoms OR male } \\
\text { condoms OR Emergency contraceptives } \\
\text { OR EC OR Pre-exposure Prophylaxis OR } \\
\text { PrEP OR post-exposure prophylaxis OR } \\
\text { PEP }\end{array}$ \\
\hline
\end{tabular}

"unintended pregnancy" OR "unwanted pregnancy" OR family planning

Domestic Violence OR Intimate Partner Violence OR Sex Offenses

Violence

Global Health

Assistance

HIV/AIDS \& STIS

Human Rights

Infectious Diseases

Key Populations

Maternal and Child Health violence OR Intimate Partner Violence OR Sex Offenses

"United States Government Agencies" OR "Federal Government" OR "United States Agency for International Development" OR "Center for Disease Control and Prevention" OR "US Department of Defense" OR "Peace Corps"

"HIV" OR "Acquired Immunodeficiency Syndrome" OR "Sexually Transmitted Diseases"

\section{"US foreign assistance" OR "Global} Health Assistance"

sexually transmitted infections OR Sexually transmitted Diseases OR HIV/ AIDS OR HIV OR AIDS OR STD OR STI

human rights

"Human Rights" OR "Human Rights Abuses"

"Communicable Diseases" OR

"Tuberculosis" OR "Malaria" OR "Zika Virus" OR "Zika Virus Infection" OR

"Hemorrhagic fever, Ebola"

Infectious Diseases OR Tuberculosis OR Malaria OR Zika OR Ebola

"Sexual Minorities" OR "Sex Workers" OR Lesbian' OR 'Gay' OR 'Bisexual' OR "Adolescent" OR "Substance Abuse, Intravenous" OR "Prisoners"

'Transexual' OR 'Transgender' OR 'Queer' OR 'Intersexual' OR 'LGBTQI' OR 'Men who have Sex with Men' OR 'MSM' OR 'Sex Workers' OR 'HIV key populations' OR 'adolescent girls' OR' young women' OR 'AGYW' OR 'people who inject drugs' OR PWID OR Prisoners

Maternal and Newborn Child Health' OR 'Maternal and Child Health'
"Maternal-Child Health Centers" OR "Maternal-Child Health Services" OR "Maternal Health Services" OR Maternal Health
Search strategy per topic (PubMed)

((Global Gag Rule) OR Mexico City Policy)

OR Protecting Life in Global Health Assistance

(((abortion) OR "Abortion, Criminal"[Mesh]) OR "Abortion, Septic"[Mesh]) OR "Abortion, Induced"[Mesh]

Advocacy

(((()“Condoms"[Mesh]) OR "Condoms, Female"[Mesh]) OR "Pre-Exposure Prophylaxis"[Mesh]) OR "Contraceptives, Postcoital"[Mesh]) OR "Post-Exposure Prophylaxis"[Mesh]) OR (((c(((condoms) OR female condoms) OR male condoms)

OR pre-exposure prophylaxis) OR PrEP)

OR emergency contraceptives) OR EC)

OR post-exposure prophylaxis)

(((“"Family Planning Services"[Mesh]) OR

"Family Planning Policy"[Mesh]) OR

"Pregnancy, Unplanned"[Mesh]) OR

"Pregnancy, Unwanted"[Mesh]) OR

(((() (unintended pregnancy) OR unwanted pregnancy) OR unplanned pregnancy)

OR family planning))

gender-based violence

((“United States Government Agencies"[Mesh]) OR "Federal Government"[Mesh]) OR "United States Agency for International Development"[Mesh]
((("HIV"[Mesh]) OR "Acquired Immunodeficiency Syndrome"[Mesh]) OR "Sexually Transmitted Diseases"[Mesh]) OR sexually transmitted infections

((("Human Rights"[Mesh]) OR "Human Rights Abuses"[Mesh])) OR Human rights

((c((IInfectious Diseases) OR

(((tuberculosis) OR malaria) OR zika)) OR

"Zika Virus Infection"[Mesh]) OR "Zika

Virus"[Mesh]) OR "Malaria"[Mesh]) OR

"Tuberculosis"[Mesh]) OR "Communicable Diseases"[Mesh]

(((((HIV Key Populations) OR "Sexual Minorities"[Mesh]) OR lesbian) OR "Sex Workers"[Mesh]) OR "Adolescent"[Mesh])

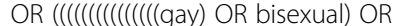
transexual) OR Queer) OR Intersexual) OR LGBTQI) OR Men who have sex with Men) OR MSM) OR Sex Workers) OR HIV key populations) OR Adolescent Girls) OR Young Women) OR AGYW) OR People who inject drugs) OR PWID)

((("Maternal-Child Health Centers"[Mesh]) OR "Maternal-Child Health Services"[Mesh]) OR (maternal and newborn child health)) OR ((maternal 
Table 7 Search Terms \& Key Words per Focus Area (Continued)

\begin{tabular}{|c|c|c|c|}
\hline Key Topics & $\mathrm{MeSH}$ & $\begin{array}{l}\text { key search words (keywords will be } \\
\text { searched TIAB search filter) }\end{array}$ & Search strategy per topic (PubMed) \\
\hline & & & and child health)) \\
\hline $\begin{array}{l}\text { Maternal Mortality \& } \\
\text { Morbidity }\end{array}$ & $\begin{array}{l}\text { "Maternal Mortality" OR "Maternal } \\
\text { Death" }\end{array}$ & $\begin{array}{l}\text { Maternal mortality' OR maternal } \\
\text { morbidity }\end{array}$ & $\begin{array}{l}\text { (("Maternal Mortality"[Mesh]) OR maternal } \\
\text { mortality) OR maternal morbidity }\end{array}$ \\
\hline $\begin{array}{l}\text { Non-Communicable } \\
\text { Diseases }\end{array}$ & $\begin{array}{l}\text { "Cholera" OR "Uterine Cervical } \\
\text { Neoplasms" }\end{array}$ & $\begin{array}{l}\text { Cholera' OR 'Cervical Cancer' OR non- } \\
\text { communicable diseases OR 'HPV' [TIAB] }\end{array}$ & $\begin{array}{l}\text { (("Cholera”[Mesh]) OR “Uterine Cervical } \\
\text { Neoplasms"[Mesh]) OR (((cervical cancer) } \\
\text { OR cholera) OR non-communicable } \\
\text { diseases) }\end{array}$ \\
\hline $\begin{array}{l}\text { Orphans \& } \\
\text { Vulnerable Children }\end{array}$ & $\begin{array}{l}\text { "Child, Orphaned" OR "Child, } \\
\text { Abandoned" }\end{array}$ & Orphans and vulnerable children [TIAB] & orphans and vulnerable children \\
\hline $\begin{array}{l}\text { Prevention of } \\
\text { Maternal To Child } \\
\text { Transmission }\end{array}$ & none & $\begin{array}{l}\text { PMTCT [TIAB] OR 'Prevention of Mother } \\
\text { to Child Transmission' }\end{array}$ & $\begin{array}{l}\text { (Prevention of Mother to Child } \\
\text { Transmission) OR PMTCT }\end{array}$ \\
\hline Reproductive Health & $\begin{array}{l}\text { "Reproductive Health" OR "Reproductive } \\
\text { Health Services" OR "Reproductive } \\
\text { Rights" }\end{array}$ & $\begin{array}{l}\text { TIAB- reproductive health OR } \\
\text { reproductive health services OR } \\
\text { reproductive rights OR sexual and } \\
\text { reproductive health and rights OR SRHR }\end{array}$ & $\begin{array}{l}\text { ((“"Reproductive Health"[Mesh]) OR } \\
\text { "Reproductive Health Services”[Mesh]) OR } \\
\text { "Reproductive Rights"[Mesh]) OR "Sex } \\
\text { Education"[Mesh] }\end{array}$ \\
\hline $\begin{array}{l}\text { Water, Sanitation, } \\
\text { and Hygiene }\end{array}$ & "Hygiene" OR "Sanitation" & $\begin{array}{l}\text { 'water, sanitation and hygiene' [TIAB] OR } \\
\text { WSH [TIAB] OR sanitation [TIAB] or } \\
\text { Hygiene [TIAB] }\end{array}$ & water sanitation and hygiene \\
\hline
\end{tabular}

Although the quantitative studies investigating the association between the GGR and abortion rates debunk the claim that the GGR reduces abortion incidence [4, 51], empirical evidence has been disregarded in the policy-making. The evidence on the GGR has consistently revealed how the policy is rupturing effective integrated services [28] and in some instances, leaving entire communities without clinic access $[36,41]$. This scoping review has provided evidence that the GGR is dismantling health systems by causing confusion about its practical implementation; unraveling integrated systems; diminishing qualified staff and crucial resources; silencing necessary advocacy voices and spaces; and reducing health service provision - including but not limited to family planning services - as well as health outcomes indicators. Policymakers can use the findings in this review to create policies based on evidence in order to effectively achieve their intended outcomes.

\section{Avenues for future research}

Knowledge of the conditions underpinning policy compliance or non-compliance is a small fraction of comprehending the GGR. More research and policy analysis are needed to understand the organizational processes and the health systems to which the GGR gets applied to ultimately explain why desired policy outcomes failed to emerge or why the unintended and harmful impacts of the GGR occurred. This evidence would be invaluable for GGR policy reform.

In order to mitigate policy harm, more empirical research is needed to understand the confusion surrounding the GGR at the individual, community, and national or global levels of the health system. More research is also needed to track and explore changes in domestic policies as a response to or consequence of the GGR.

\section{Limitations}

The search strategy included only articles published in English. This strategy poses a potential limitation if relevant works in other languages were removed. The majority of the literature in this review is grey and has limited discussion and presentation of the methodology. Given the methodological constraints, the results of this scoping review should be cautiously interpreted. For example, few of the studies $[4,8,51]$ used population data to explore the association between the GGR and abortion rates. There is a scarcity of abortion data, especially in countries in which it is criminalized and reporting systems may not exist [67].

\section{Conclusion}

The evidence shows that even before recent expansion and reinstatement of the GGR, the previous iterations of the policy deteriorated health system functions beyond family planning programs. At the micro-level, providerclient interactions were affected as health care providers could not share the full range of reproductive information and options. At the meso-level, civil society was silenced from abortion advocacy. At the macro-level, coalition spaces dissolved and entire organizations lost funding, which had crippling effects for beneficiaries of health services, organizational functions, and health systems as a whole.

The policy's development and implementation processes are flawed, and the consequences of these flaws 
are experienced by low- and middle-income countries (LMICs) who are beneficiaries of U.S. foreign assistance. Policy analysis and more empirical research that investigates the interactions of the policy's impact at all levels of the health system would generate the evidence needed to change the conditions of the GGR and mitigate its harms.

\section{Abbreviations}

AIDS: Acquired Immunodeficiency Syndrome; ART: Antiretroviral Therapy; CHANGE: Center for Health and Gender EquityGBVGender-based Violence; GGR: Global Gag Rule; HIV: Human Immunodeficiency Virus; IPPF: International Planned Parenthood Federation; LMICs: Low- and MiddleIncome Countries; MCH: Maternal and Child Health; MCP: Mexico City Policy; MSI: Marie Stopes International; NGO: Non-governmental Organization; PEPFAR: President's Emergency Plan for AIDS Relief; PLGHA: Protecting Life in Global Health Assistance; SRHR: Sexual and Reproductive Health and Rights; TB: Tuberculosis; USAID: United States Agency for International Development; VCT: Voluntary Counseling and Testing; WASH: Water, Sanitation and Hygiene

\section{Acknowledgments}

The authors would like to thank Serra Sippel (CHANGE), Beirne Roose-Snyder (CHANGE), and Kate Segal (CHANGE) for their intellectual contributions to this research. The authors would further like to thank members of the GGR research group, especially Emily Maistrellis and Marta Schaff (Heilbrunn Department of Population and Family Health, Columbia University Mailman School of Public Health) for their input on the methodological design.

\section{Authors' contributions}

CM conducted the peer-review searches, and analyzed and coalesced the studies in this review. RG conducted the grey literature searches and was a major contributor in writing the manuscript. BC oversaw the design of the review and contributed to writing the manuscript. All authors read and approved the final manuscript.

\section{Funding}

Not applicable.

\section{Availability of data and materials}

The search strategies generated for this review are available from the corresponding author upon reasonable request. An example of the strategy for Pubmed searches is also available.

\section{Ethics approval and consent to participate}

Not applicable.

\section{Consent for publication}

Not applicable.

\section{Competing interests}

The authors declare that they have no competing interests.

\section{Author details}

${ }^{1}$ Biomedical and Research Training Institute (BRTI), 10 Seagrave Rd, Avondale, Harare, Zimbabwe. 'London School of Hygiene and Tropical Medicine (LSHTM), London, UK. ${ }^{3}$ A Wider Circle, Silver Spring, USA. ${ }^{4}$ Center for Health and Gender Equity, Washington, DC., USA.

Received: 12 May 2019 Accepted: 25 July 2019

Published online: 29 August 2019

\section{References}

1. Administration RRR. Policy Statement of the United States of America at the United Nations International Conference on Population, Mexico, 1984. Washington, DC: The White House; 1984.

2. (USAID) USAID. Standard provisions for nongovernmental organizations: a mandatory reference for ADS. Washington D.C.: USAID; 2017.

3. Donald J Trump Administration. Presidential Memorandum Regarding the Mexico City Policy [press release]. Washington DC: The White House, 2017.
4. Jones KM. Evaluating the Mexico City policy: how US foreign policy affects fertility outcomes and child health in Ghana; 2011.

5. Law SA, Rackner LF. Gender Equality and the Mexico City Policy. NYUJ Int'l L \& Pol. 1987:20:193

6. Leitner Center for International Law and Justice / Fordham Law School. Exporting Confusion: U.S. foreign policy as an obstacle to the implementation of Ethiopia's liberalized abortion law. New York: Fordham Law School. New York: Fordham Law School; 2010.

7. Neier A. The right to free expression under international law: implications of the Mexico City Policy. NYUJ Int'l L \& Pol. 1987;20:229.

8. PAl. Access Denied: Impact of the Global Gag Rule in Zambia: PAl; 2006.

9. PAl. Trump's Global Gag Rule and Senegal. USA: PAl; 2017.

10. PAl. Trump's Global Gag Rule - A Monstrous Policy. 2017.

11. Bingenheimer JB, Skuster P. The foreseeable harms of Trump's global gag rule. Stud Fam Plan. 2017;48(3):279-90.

12. Singh JA, Karim SS. Trump's "global gag rule": implications for human rights and global health. Lancet Glob Health. 2017;5(4):e387-e9.

13. CHANGE. Prescribing Chaos in Global Health: the global gag rule from 1984-2018. Washington DC: Center for Health and Gender Equity; 2018.

14. Arksey H, O'Malley L. Scoping studies: towards a methodological framework. Int J Soc Res Methodol. 2005;8(1):19-32.

15. Levac D, Colquhoun H, O'Brien KK. Scoping studies: advancing the methodology. Implement Sci. 2010;5:69.

16. Alliance for Health Policy and Systems Research. Health Policy and systems research: A Methodology Reader. Geneva: World Health Organization; 2012.

17. Green J, Thorogood N. Analyzing qualitative data. Qualitative methods for Health Research. London: Sage Publications; 2004. p. 195-228.

18. Asiedu E, Nanivazo M, Nkusu M. Determinants of foreign aid in family planning: how relevant is the Mexico City policy? : WIDER working paper; 2013.

19. Blane J, Friedman M. Mexico City policy implementation study. Arlington, Virginia: Population Technical Assistance Project, Dual and Associates, Inc. International Science and Technology Institute, Inc.; 1990. p. 1990.

20. Bogecho D, Upreti M. The global gag rule--an antithesis to the rights-based approach to health. Health Hum Rights. 2006;9(1):17-32.

21. Camp S. The impact of the Mexico City policy on women and health care in developing countries. NYUJ Int'l L \& Pol. 1987;20:35.

22. Carroll LM. The Effects of the Mexico City Policy on Antenatal Care and Skilled Birth Attendance in Developing Countries North Carolina: University of North Carolina at Chapel Hill; 2012

23. Chávez S, Coe A-B. Emergency contraception in Peru: shifting government and donor policies and influences. Reprod Health Matters. 2007;15(29):139-48.

24. Choudhury SM. Evaluating the Mexico City policy: unintended consequences in Ghana. Washington, DC: Georgetown University; 2012.

25. Crane BB, Dusenberry J. Power and politics in international funding for reproductive health: the US global gag rule. Reprod Health Matters. 2004; 12(24):128-37.

26. Crimm NJ. The global gag rule: undermining national interests by doing unto foreign women and NGOs what cannot be done at home. Cornell Int'I LJ. 2007:40:587.

27. Center for Reproductive Rights. Expanded Global Gag Rule Limits Women's Rights and Endangers Their Well-being. Washington D.C.: CRR; 2009.

28. Curtis C, Farrell B, Ahlborg J. Cambodia Postabortion Care Program. Final report of findings and recommendations. Cambodia trip report: dates April 25, 2005 to May 6, 2005. Washington, D.C.: United States Agency for International Development [USAID], Bureau for Global Health, Office of Population and Reproductive Health, 2005;2005.

29. Ernst J, Mor T. Breaking the silence: the global gag rule's impact on unsafe abortion. New York: Center for Reproductive Rights; 2003. p. 2003.

30. Foster SC. Trends in condom use: the association in Malawi of condom use with AIDS knowledge and the relationship to the global gag rule. Washington, DC: Georgetown University; 2009.

31. Fox GH. American population policy abroad: the Mexico City abortion funding restrictions. NYUJ Int'l L \& Pol. 1985;18:609.

32. Gezinski LB. The Global Gag Rule: Impacts of conservative ideology on women's health. International Social Work 2012;55(6):837-49.

33. Jones AA. The Mexico City policy and its effects on HIV/AIDS Services in Subsaharan Africa. BC Third World LJ. 2004;24:187.

34. Jones KM. Contraceptive supply and fertility outcomes: evidence from Ghana. Econ Dev Cult Chang. 2015;64(1):31-69. 
35. Bendavid E, Avila P, Miller G. United States aid policy and induced abortion in sub-Saharan Africa. Bull World Health Organ. 2011;89(12):873-0c.

36. PAl. Access Denied: Impact of the Global Gag Rule in Kenya. Washington, DC: PAl; 2006

37. PAl. Access Denied: Impact of the Global gag Rule in Nepal. Washington, DC: PAl; 2006

38. Nowels L. International family planning: the "Mexico City" policy. Updated April 2, 2001. CRS Report for Congress. Washington, D.C: United States Library of Congress, Congressional Research Service; 2001. p. 2001.

39. PAl. Access denied: impact of the global gag rule in Ghana. Washington, DC: PAl; 2005

40. PAI. The Global gag Rule \& Maternal Deaths due to unsafe abortion. USA: PAl; 2017.

41. Seevers RE. The politics of gagging: the effects of the global gag rule on democratic participation and political advocacy in Peru. Brook J Int'I L. 2005; 31:899.

42. Skuster P. Advocacy in whispers: the impact of the USAID global gag rule upon free speech and free association in the context of abortion law reform in three east African countries. Mich J Gender \& L. 2004;11:97.

43. Barot S, Cohen SA. The global gag rule and fights over funding UNFPA: the issues that won't go away. Guttmacher Policy Rev. 2015;18(2):27-33.

44. Barot S. When antiabortion ideology turns into foreign policy: how the global gag rule erodes health, ethics, and democracy. Policy report. Washington, D. C: Guttmacher Institute; 2017.

45. Cohen SA. The reproductive health needs of refugees and displaced people: an opening for renewed U.S. leadership. Washington, DC: Guttmacher Institute; 2009. Contract No. p. 3.

46. Cohen SA. U.S. Overseas Family Planning Program, Perennial Victim of Abortion Politics, Is Once Again Under Siege. Washington, DC: Guttmacher Institute; 2011. Contract No.: 4.

47. van Dalen HP. Designing global collective action in population and HIV/ AIDS programs, 1983-2002: has anything changed? World Dev. 2008;36(3): 362-82.

48. Rodgers, Yana Van Der Meulen. The Global Gag Rule and Women's Reproductive Health : Rhetoric versus Reality. Chapter 6: Impacts of the Global Gag rule- new Estimates. 2018. Print. Oxford Scholarship Online.

49. Justice LCflLa. Exporting Confusion. U.S. foreign policy as an obstacle to the implementation of Ethiopia's liberalized abortion law. New York: Fordham law school. New York: Fordham Law School; 2010.

50. PAl. Access denied: US restrictions on international family planning. Washington, DC: PAl; 2003.

51. PAl. Access Denied: Impact of the Global Gag Rule in Ethiopia. Washington, DC: PAl; 2005

52. PAl. Access denied: impact of the global gag rule in Tanzania. Washington, DC: PAl; 2005

53. PAl. Access Denied: Impact of the Global Gag Rule in Zimbabwe. Washington, DC: PAl; 2005

54. Ganatra B, Gerdts C, Rossier C, Johnson BR Jr, Tunçalp Ö, Assifi A, et al. Global, regional, and subregional classification of abortions by safety, 201014: estimates from a Bayesian hierarchical model. Lancet. 2017;390(10110): 2372-81.

55. Kent Buse NMGW. Policy Implementation. In: Making Health Policy [Internet]. England: Open University Press. 1. Understanding Public Health: 2005. p. 120-37.

56. Pülzi H, O T. Implementing public policy. In: F F GJM, MS S, editors. Handbook of public policy analysis: theory, politics, and methods. Boca Raton: CRC Press; 2006

57. Berlan D, Shiffman J. Holding health providers in developing countries accountable to consumers: a synthesis of relevant scholarship. Health Policy Plan. 2012;27(4):271-80.

58. Erasmus E. Important policy analysis theories in-brief: street-level bureaucracy. In: Health policy analysis guidance note. Cape Town: University of Cape Town, Programme HPaS; 2011.

59. Gilson L, Erasmus E, Borghi J, Macha J, Kamuzora P, Mtei G. Using stakeholder analysis to support moves towards universal coverage: lessons from the SHIELD project. Health Policy Plan. 2012;27(suppl 1):i64-76.

60. WALT G, GILSON L. Reforming the health sector in developing countries: the central role of policy analysis. Health Policy Plan. 1994;9(4):353-70.

61. Government of South Africa. Choice on Termination of Pregnancy Act, [No. 92 of 1996]- G 1760. South Africa: President's Office; 1996.
62. U.S. Congress. United States Leadership Against HIV/AIDS, Tuberculosis, and Malaria Act of 2003; 2003. p. 108-25.

63. Bendavid E, Bhattacharya J. The President's emergency plan for AIDS relief in Africa: an evaluation of outcomes. Ann Intern Med. 2009;150(10):688-95.

64. PEPFAR. PEPFAR 2017 Annual Report to Congress. Washington D.C: Office of the U.S. Global AIDS Coordinator and Health Diplomacy; 2017.

65. PEPFAR. PEPFAR Latest Global Results, Fact Sheet. Washington DC: Office of the U.S. Global AIDS Coordinator and Health Diplomacy; 2018.

66. amfAR. Impact of the Mexico City policy on PEPFAR. Washington DC: amfAR Public Policy Office; 2018.

67. Sedgh G, Bearak J, Singh S, Bankole A, Popinchalk A, Ganatra B, et al. Abortion incidence between 1990 and 2014: global, regional, and subregional levels and trends. Lancet. 2016;388(10041):258-67.

\section{Ready to submit your research? Choose BMC and benefit from:}

- fast, convenient online submission

- thorough peer review by experienced researchers in your field

- rapid publication on acceptance

- support for research data, including large and complex data types

- gold Open Access which fosters wider collaboration and increased citations

- maximum visibility for your research: over $100 \mathrm{M}$ website views per year

At $\mathrm{BMC}$, research is always in progress.

Learn more biomedcentral.com/submissions 